\title{
Noise pollution and housing markets: A spatial hedonic analysis for La Plata City ${ }^{1}$
}

Juan Ignacio Zoloa ${ }^{2}$

\section{Resumen}

El problema de la contaminación acústica afecta a la calidad de vida en gran parte de las ciudades del mundo. De hecho, el excesivo nivel de ruido es un factor de riesgo medioambiental, el cual puede causar problemas importantes sobre la salud de las personas, como por ejemplo, problemas de sueño y aprendizaje, problemas de memoria, falta de motivación e incremento en la irritabilidad y agresividad. Este trabajo analiza el valor que las personas le asignan a vivir en un ambiente con menores niveles de ruido. Para ello se utilizan modelos de precios hedónicos, los cuales permiten estimar la disponibilidad marginal a pagar por reducir el nivel de exposición a la contaminación acústica. El principal resultado de este trabajo muestra la relevancia del problema: las personas están dispuestas a pegar un $1.9 \%$ menos por una casa por cada decibel adicional de ruido alrededor de la propiedad. Este resultado es muy importante al momento de diseñar políticas de mitigación de ruido, de forma de poder comparar los beneficios derivados de la mitigación con los costos de implementar dichas políticas.

Palabras claves: contaminación acústica, mercado inmobiliario, modelos hedónicos, Argentina.

\section{Abstract}

Several cities around the world are affected by high levels of noise pollution. In fact, noise pollution is one of the main problems affecting the quality of life in cities. In this sense, noise, understood as an environmental stressor, can cause significant health problems, including sleep and learning disorders, memory troubles, lack of motivation and increase in irritability and aggressiveness. This work analyzes the value that individuals place on living in quieter areas. Using hedonic price models, we obtained an accurate assessment of the marginal willingness to pay of individuals to reduce noise pollution. The main result highlight the relevance of this topic: a buyer is willing to pay around $1.9 \%$ less for each decibel of noise around the house. Such result is especially relevant in the design of noise mitigation policies, as it determines whether the benefits of the policies designed to reduce noise pollution exceed their implementation costs.

Keywords: noise pollution, housing markets, hedonic price models, Argentina

JEL: D62, H40, I10, Q51, Q53, R21

DOI: https://doi.org/10.46553/ensayos.3.2.2020.p129-152

Fecha de recepción: 18/05/2020; Fecha de aceptación: 21/07/2020

\footnotetext{
${ }^{1}$ This work was conducted as part of the requirements for the degree of Doctor en Economía, Facultad de Ciencias Económicas, Universidad Nacional de La Plata.

${ }^{2}$ Universidad Nacional de La Plata. Email: juan.zoloa@econo.unlp.edu.ar
} 


\section{Introduction}

The world is becoming increasingly urbanized. As today, more than half the world's population live in cities, and that share is projected to rise to 68 percent by 2050 (UN, 2018). Cities are drivers of economic prosperity, contributing about 60 percent of global GDP. However, on the down side, about 70 percent of global carbon emissions and other environmental externalities are generated in urbanized areas. In recent decades urbanization rates have been rising throughout the developing world without suitable infrastructure and public services, worsening environmental pollution. This process has raised global concerns about the actual and future quality of life of city dwellers. As a result, the United Nations has included the objective of achieving "sustainable cities and communities" as one of their sustainable development goals. ${ }^{3}$

Large and medium-size cities are usually affected by high levels of air and noise pollution arising mainly from traffic, industrial activities, and operations related to construction. In fact, air and noise pollution is one of the main concerns of people who live in cities. In this sense, noise pollution, understood as a noise level above tolerable limits is considered as an environmental stress factor. Medical studies have carefully documented the detrimental effect of noise on sleep habits, learning, memory, and motivation, the ability to solve problems, and also irritability and aggressiveness. Even though a person might successfully find a response to noise exposure, it can generate permanent side effects with negative health consequences and thus interfere with the productivity and general wellbeing of the individual.

Data from the World Health Organization (WHO, 2011) show that at least 1 million healthy life years are lost every year from traffic-related noise pollution in the Western European countries. Sleep disturbance and annoyance related to road traffic noise constitute most of the burden of environmental noise in Western Europe. ${ }^{4}$ On the other hand, although several developed countries have implemented policies to mitigate noise exposure in the recent decades, it has been estimated that over $20 \%$ of the European Union (around 80 million people) are exposed to noise levels considered above acceptable limits that cause discomfort, sleep disturbance and possible adverse health effects. In addition, 170 million people live in what is known as "gray areas" where noise levels cause serious disturbances during the day (WHO, 2011). Unfortunately, there are no similar studies for Argentina or other Latin American country.

The aim of this work is to obtain a precise value of the marginal willingness to pay of individuals to reduce noise pollution in a mid-size city in a developing country; La Plata, Argentina. In order to achieve this goal, we use spatial hedonic price models, a standard methodology for valuing environmental disamenities. The main result highlights the importance of the noise pollution on real estate buyers' willing to pay: each additional decibel of noise reduces house prices in about 1.9 percent.

\footnotetext{
${ }^{3}$ https://sdgs.un.org/goals/goal11

${ }^{4}$ The years of life lost (Disability Adjusted DAYLs) as a result of environmental noise are 61000 years for ischaemic heart disease, 45000 years for cognitive impairment of children, 903000 years for sleep disturbance, 22000 years for tinnitus and 587000 years for annoyance.
} 
An accurate assessment of the benefits associated with reduced levels of noise pollution is especially relevant in the design of noise mitigation policies, as it determines whether the benefits of these policies exceed the costs associated with its implementation. It is therefore important to use the most appropriate method to estimate these benefits and to determine the accuracy of the estimated values. From a policy perspective it is also very important to understand how sensitive these estimates are to the methods used. Therefore, in this paper we also analyse how sensitive are the results to alternative noise maps produced with fewer measurement locations.

The paper has a standard organization. The next section describes previous studies related to noise pollution and the housing market. The following section presents the empirical strategy. The data used in the analysis is described in the fourth section, followed by the main results. In the sixth section a sensitivity analysis is performed and finally, conclusions are presented.

\section{Literature review on noise pollution}

The hedonic approach, originally developed by Rosen (1974), has become an established and standard methodology to monetize environmental amenities. After the classical studies on pollution by Ridker and Henning (1967) and Harrison and Rubinfeld (1978), a voluminous literature dealing with theoretical, methodological and empirical aspects of valuing environmental amenities has emerged. For example, Navrud (2002) presents a good review of this literature related to undercover the economic value of noise pollution.

Most of the previous literature has analysed the impact of noise pollution on the housing market by looking at the distance from individual houses to an important source of noise, such as avenues with heavy traffic, train stations or airports. The usual hypothesis in these studies is that, holding other factors that affect housing prices constant, those houses exposed to lower levels of noise pollution should have a higher market price. However, given the large differences in approaches, settings, data, noise measurements, and time periods analysed, among others, the results reported by these studies show a wide range of estimates of the economic impacts of noise pollution. In this context, meta-analysis techniques are particularly useful for comparing estimates produces by studies with heterogeneous settings. The aim of a meta-analysis is to identify potential factors that explain differences in estimated impacts, and to assess the consistency of the results. A review of 22 studies on the effect of the noise generated by road traffic on housing values shows a reduction in prices ranging from 0.08 percent to 2.22 percent for each additional decibel. While in studies based on distances to airports the reported estimates range from 0.06 percent to 2.30 percent (Hawkins, 1999; Bateman et al., 2000; and Day, 2001). Another meta-analysis by Bertrand (1997), based on 16 estimates from 9 international studies, indicates that the average impact is a price reduction of 0.64 percent per additional decibel. The variations between the studies are mainly explained by differences in income levels. 
One of the settings most studied is the proximity to an airport. In this regard, a metaanalysis done by Nelson (2004) from 20 studies for the United States and Canada, found that the average impact on house prices is -0.58 percent per additional decibel. The study also shows significant differences between estimates form the US and Canada, and between model specifications, while the other factors considered (such as sample size or the date of the study) have little or no effect. In particular, the effect of noise pollution from airports is a price discount of approximately 0.5-0.6 percent by decibel for the United States and 0.8-0.9 percent for Canada.

It is important to notice that a positive correlation between property price and noise is also possible. For instance, real estate properties in commercial areas surrounded by bars and restaurants and lot of people passing by, tend to be noisier and also more expensive. In those cases, more noise may be correlated with more economic activity and therefore the effect could run in either direction. Another typical example of this positive correlation pertains those houses located in front of a park, which tend to be more expensive, but also noisier since parks might attract many people. Therefore, it is very important in the empirical analysis to control for those neighbourhood characteristics that might be both correlated with prices and noise levels.

Regarding previous studies for Argentina, there are only two other papers attempting to estimate the economic value from noise disamenities. The work done by Angeletti (2000) for the city of La Plata, found that noise and air pollution do not play a major role in determining the price of housing, while the analysis by Conte Grand (2001) for the city of Buenos Aires, shows a negative correlation with prices, but only significant at a 15 percent confidence level. A common characteristic in those papers is that they do not directly measure noise pollution. Given the lack of accurate and comparable data on environmental pollution, both studies used public transport, defined as the product of the number of bus lines and their frequency, as a proxy for noise and air pollution. An advantage of our work over previous studies is that we use direct measurements of noise levels, which are both highly accurate and spatially comparable across a mid-size city.

The recent empirical literature on the valuation of environmental amenities has accompanied the methodological evolution in hedonic price models. In particular, several studies in recent years explicitly model the spatial interactions between housing units (see Palmquist, 2005). In the next section we laid out the methodology.

\section{Empirical strategy}

In this paper we use spatial hedonic price models to analyse the relationship between housing prices and noise pollution. The basic idea behind this type of models is that the price of a composite product depends on the bundle of its constituent parts or characteristics. In the case of a house, these constituent parts are related to its structure (size, number of rooms, whether it has a yard or not, parking space, general condition, etc.), the neighbourhood attributes (quality of schools, distance to commercial areas and parks, access to public transportation or roads, crime rates, 
etc.), the surrounding environmental quality (noise and other forms of pollution) and property taxes. The hedonic model rests on the idea that the observed variability in housing prices can be attributed to the variability of observable and unobservable characteristics. Therefore, by regressing house values on its characteristics it is possible to estimate the implicit price of each attribute. In particular, we are interested in estimating people's willingness to pay for marginal changes in noise pollution.

As mentioned before, hedonic price models relate the price of houses to their characteristics. Since these models are based on observed behaviour, i.e. house purchases, they are part of a type of valuation approaches called "revealedpreference" methods. In the hedonic framework the utility function is defined as a function of housing, environmental quality, noise pollution, socioeconomic characteristics and a composite consumption good. If individuals maximize their utility such behaviour would lead to equate the marginal utility of each characteristic to its marginal price. The derivative of the hedonic price equation with respect to each explanatory variable is its implicit marginal price. This marginal implicit price can be interpreted as the marginal willingness to pay, assuming the housing market is in equilibrium (Rosen, 1974).

One important caveat of the hedonic price model is that there exists symmetric information regarding housing attributes between buyers and sellers of real estate properties. In particular, this means that both buyers and sellers know the true level of noise pollution. If that is the case it is possible that, ceteris paribus, those houses located in areas with lower noise pollution will have this benefit capitalized on their price.

From the methodological point of view, an important characteristic of the housing market is the presence of spatial relationships among houses. These spatial relationships can be of two types. The first one is spatial dependence which happens whenever a variable tends to be correlated for geographically close units. In real estate markets it may appear when either the prices or the characteristics of houses that are close are more like each other than those from houses that are farther apart. In addition, spatial dependence may also stem from measurement problems in explanatory variables, omitted variables, and other forms of model misspecifications (Anselin, 1988). The second type is called spatial heterogeneity, and it implies that the functional forms and the parameters are not homogeneous and vary according to the location. Spatial heterogeneity can originate from characteristics of the demand, the supply, institutional barriers, or racial discrimination all of which can make the distribution of house prices differ throughout space. A detailed description of spatial models can be found in Anselin (1988) and LeSage and Pace (2009).

Our empirical strategy begins with the estimation of the hedonic price equation by ordinary least squares (OLS). This equation relates the price of a house to their characteristics. Formally, the following model is estimated:

$$
P=X \beta+\mu
$$


Where $P$ is a $N$ by 1 vector containing property prices, $X$ is a $N$ by $K$ matrix of house characteristics, such as its size, the number of bedrooms and bathrooms, the overall condition, and the age since its construction along with the neighbourhood socioeconomic characteristics and, of course, the noise level. The error term is $\mu$.

After obtaining the errors of the OLS estimation, Lagrange tests proposed by Anselin (2005) are performed to detect the model that best explain the spatial interactions. Based on the results from these tests the model used in this paper is the Spatial Error Model (SEM). As Table 1 shows the Lagrange multiplier robust $L M_{e r r o r}$ is the only significant which allows rejecting the null hypothesis of no spatial autocorrelation in favor of the SEM specification. A more detailed explanation of the spatial models, the test and their null hypothesis can be found in Anselin (2005), Herrera (2015) and Zoloa (2015).

Table 1: Spatial diagnosis

\begin{tabular}{lllcc}
\hline \multirow{2}{*}{ Model } & \multicolumn{3}{c}{ Statistic } \\
\cline { 3 - 5 } & & I de Moran & Lagrange multiplier & Robust Lagrange multiplier \\
\hline 1 & Spatial error & $12.632 * * *$ & $147.441^{* * *}$ & $83.494^{* * *}$ \\
& Spatial lag & & $64.177^{* * *}$ & 0.23 \\
2 & Spatial error & $12.467 * * *$ & $141.846 * * *$ & $83.494 * * *$ \\
& Spatial lag & & $56.316^{* * *}$ & 0.23 \\
\multirow{2}{*}{3} & Spatial error & $12.252 * * *$ & $141.846 * * *$ & $85.538^{* * *}$ \\
& Spatial lag & & $56.316^{* * *}$ & 0.009 \\
4 & Spatial error & $12.357 * * *$ & $136.747 * * *$ & $84.606 * * *$ \\
& Spatial lag & & $54.898^{* * *}$ & 0 \\
5 & Spatial error & $12.28 * * *$ & $136.746 * * *$ & $84.15^{* * *}$ \\
& Spatial lag & & $52.635^{* * *}$ & 0.039 \\
\hline
\end{tabular}

Note: ${ }^{*}$ significant at $10 \%$; ${ }^{* *}$ significant at $5 \% ;{ }^{* * *}$ significant at $1 \%$. Model 1 includes controls for high and moderate risk of flooding. Model 2 includes controls for high and moderate risk of flood, average wage and proportion of owners. Model 3 includes controls for high and moderate risk of flooding, unemployment rate and proportion of owners. Model 4 includes controls for high and moderate risk of flood, average wage and unemployment rate. Model 5 includes controls for high and moderate risk of flood, average wage, unemployment rate and proportion of owners (see Section IV for a description of the data).

The SEM model has the following specification:

$$
\begin{gathered}
P=X \beta+\mu \\
\mu=\lambda W \mu+\varepsilon
\end{gathered}
$$

where $P, X$, and $R$ are the matrix defined above and $\lambda$ is the coefficient in the spatial autoregressive structure of the disturbance $\mu$. The innovations $\varepsilon$ are assumed independent and identically distributed (idd) or independent but heteroskedastic where heteroskedasticity has an unknown form.

The parameter $\lambda$ shows the intensity of the spatial relationship through the error term. A positive value indicates that a given shock will not only affect the region in which it 
was originated, but it will be transmitted throughout space. An alternative explanation is related to omitted spatially-correlated variables, or measurement errors. ${ }^{5}$ It is important to note that the interpretation of SEM coefficients is the same as that of the OLS models.

The matrix $W, N$ by $N$ dimension, is called the spatial weights matrix. The literature has documented several specifications that can be broadly classified as "contiguity" and "distance-based" matrices. ${ }^{6}$ In this paper we construct a spatial weight matrix using the distance decay matrix, where $\left[w_{i j}=d_{i j}^{-\alpha}\right]$. This matrix assigns nearby houses a higher weight than those that are further away. In particular, we choose an alpha parameter equal to 2, which means that the weight is the inverse distance squared between any two observations. ${ }^{7}$

The SEM model to estimate may be written as follows:

$$
P=X \beta+(I-\lambda W)^{-1} \varepsilon
$$

If the previous model correctly specifies the data generating process, the OLS estimation will be inappropriate. In these cases, errors may be distributed in groups (similar values in some specific areas) in a manner resulting in continuous or discrete (space systems) spatial heterogeneity when the model is not properly specified. Therefore, it can lead to problems of inefficiency but not bias if we estimate an OLS model instead of a SEM one.

\section{Data}

We study the effect that noise pollution has on house prices using data from the city of La Plata, Argentina. According to the 2010 national census, La Plata has a total population of about 650 thousand inhabitants and almost a quarter million residential properties. The city is located in the northeaster portion of the Province of Buenos Aires, about 60 kilometres south the city of Buenos Aires.

\section{IV.1. Houses}

The data used in this paper include 697 single-family houses on sale between November 2009 and September 2010 (247 in November 2009, 243 from May 2010 and 207 in September 2010). The data was gathered by looking at single-occupancy houses for sale advertised by 28 real estate agencies, which represent about $95 \%$ of

\footnotetext{
${ }^{5}$ Measurement error may occur when the spatial unit of observation does not coincide with the spatial extent of the economic behaviour, and then systematically relates to location.

${ }^{6}$ These matrices are often row-standardized to constrain the sum of elements of each row to be equal to 1

${ }^{7}$ This type of weighting matrix is the most commonly used in spatial hedonic models applied to urban real estate markets. Alternatively, $\alpha=1$ implies that the weight decreases linearly with the distance between two observations. Other weighting schemes assigns equal weights to every unit within a certain radius (often refereed as short-distance or radial-distance weights) and zero otherwise, but this might be problematic given the discontinuity implied by the definition. Other common alternative is to use the $\mathrm{n}$ nearest neighbours, often treating equally each neighbour.
} 
the local housing market. These agencies publish their offerings in an online information system called SIOC (Sistema Inmobiliario de Ofertas por Computación). This system provides information such as the exact location of a property, its asking price, the dimension of the house, and other structural characteristics including the number of bedrooms and bathrooms, age of the structure and his condition, and the availability of parking space. In addition to the information obtained from the SIOC, we calculate the driving distance and travel time from the property to the central business district (CBD) ${ }^{8}$ and whether it is located on an avenue. Census 2001 provided a series of variables on socioeconomic and demographic characteristics, at census tracts level; we included some of them as contextual variables: average hourly wage, unemployment rate and proportion of home and land owners. The flooding risk data comes from a study produced by the Instituto de Geomorfologa y Suelos (IGyS) of the Universidad Nacional de La Plata, during the early 2000s, Hurtado et al. (2006). A more detailed discussion about the housing data used in this study can be found in Rabassa and Zoloa (2016). ${ }^{9}$

Table 2: Descriptive Statistics

\begin{tabular}{lccccc}
\hline Variables & Mean & $\begin{array}{c}\text { Standard } \\
\text { deviation }\end{array}$ & Minimum & Maximum & Source \\
\hline Home price (US dollars PPP 2005) & 132,770 & 75,731 & 19,139 & 450,000 & $f 1$ \\
Noise (LEQ) & 71 & 1.48 & 66 & 76 & $f 2$ \\
Currency (=1 US dollars) & $72 \%$ & $45 \%$ & $0 \%$ & $100 \%$ & $f 1$ \\
Lot size (square meters) & 311 & 225 & 40 & 2,160 & $f 1$ \\
House size (square meters) & 198 & 106 & 32 & 800 & $\mathrm{f} 1$ \\
Stories (number) & 1.7 & 0.6 & 1.0 & 4.0 & $\mathrm{f} 1$ \\
Bedrooms (number) & 3.0 & 1.1 & 1.0 & 10.0 & $\mathrm{f} 1$ \\
Baths (number) & 2.3 & 1.2 & 1 & 5.0 & $\mathrm{f} 1$ \\
House age (years) & 35.2 & 17.4 & 0 & 100.0 & $\mathrm{f} 1$ \\
Garages (number & $77 \%$ & $42 \%$ & $0 \%$ & $100 \%$ & $\mathrm{f} 1$ \\
Condition: good (=1 yes) & $62 \%$ & $49 \%$ & $0 \%$ & $100 \%$ & $\mathrm{f} 1$ \\
Condition: excellent (=1 yes) & $27 \%$ & $44 \%$ & $0 \%$ & $100 \%$ & $\mathrm{f} 1$ \\
Time 2 (May) & $35 \%$ & $48 \%$ & $0 \%$ & $100 \%$ & $\mathrm{f} 1$ \\
Time 3 (September) & $30 \%$ & $46 \%$ & $0 \%$ & $100 \%$ & $\mathrm{f} 1$ \\
Distance to CBD (Minutes) & 8.1 & 2.6 & 0.3 & 14.2 & $\mathrm{f3}$ \\
Distance to CBD (Km) & 3.2 & 1.3 & 0.1 & 6.3 & $\mathrm{f3}$ \\
On avenue (=1 yes) & $18 \%$ & $39 \%$ & $0 \%$ & $100 \%$ & $\mathrm{f4}$ \\
Average hourly wage (US dollars PPP 2005) & 181 & 12 & 143 & 212 & $\mathrm{f5}$ \\
Unemployment rate & $17 \%$ & $5 \%$ & $4 \%$ & $42 \%$ & $\mathrm{f5}$ \\
Proportion of home and Land owners & $71 \%$ & $9 \%$ & $40 \%$ & $86 \%$ & $\mathrm{f5}$ \\
Flooding risk: high & $8 \%$ & $28 \%$ & $0 \%$ & $100 \%$ & $\mathrm{f6}$ \\
Flooding risk: moderate & $51 \%$ & $50 \%$ & $0 \%$ & $100 \%$ & $\mathrm{f6}$ \\
\hline
\end{tabular}

Note: property prices are in US dollars. The sources are f1: Property Special Computer System (SIOC); f2: Laboratory of Acoustics and Lighting of the Committee for Scientific Research of the Province of Buenos Aires; f3: SIOC and geospatial tools; f4: own calculations based on address; f5: Census 2010 census level Radio; f6: Geomorphology and Soils Institute and geospatial tools.

Table 2 presents descriptive statistics for those houses used in this paper. The average home price is around U\$D 132,770 and have an average floor area of 198 square meters. The average car time to the business centre is 8.1 minutes (or 3.2 kilometres). The property has an average of 3 bedrooms, 2 bathrooms and just over

\footnotetext{
${ }^{8}$ Calculations were performed with Stata command traveltime, which finds travel distances and time between points by alternative means of transport using Google Maps.

${ }^{9}$ Rabassa and Zoloa (2016) also discuss the potential drawbacks from using asking prices and not transaction prices in the context of the La Plata's housing market.
} 
35 years since its construction. In addition, $18 \%$ of the houses are located on an avenue, $77 \%$ have their own parking space. There are $8 \%$ of the houses located on high flooding risk area and $51 \%$ on moderate risk zones. The spatial distribution of the data used is shown in Figure 1.

Figure 1: Spatial distribution of houses

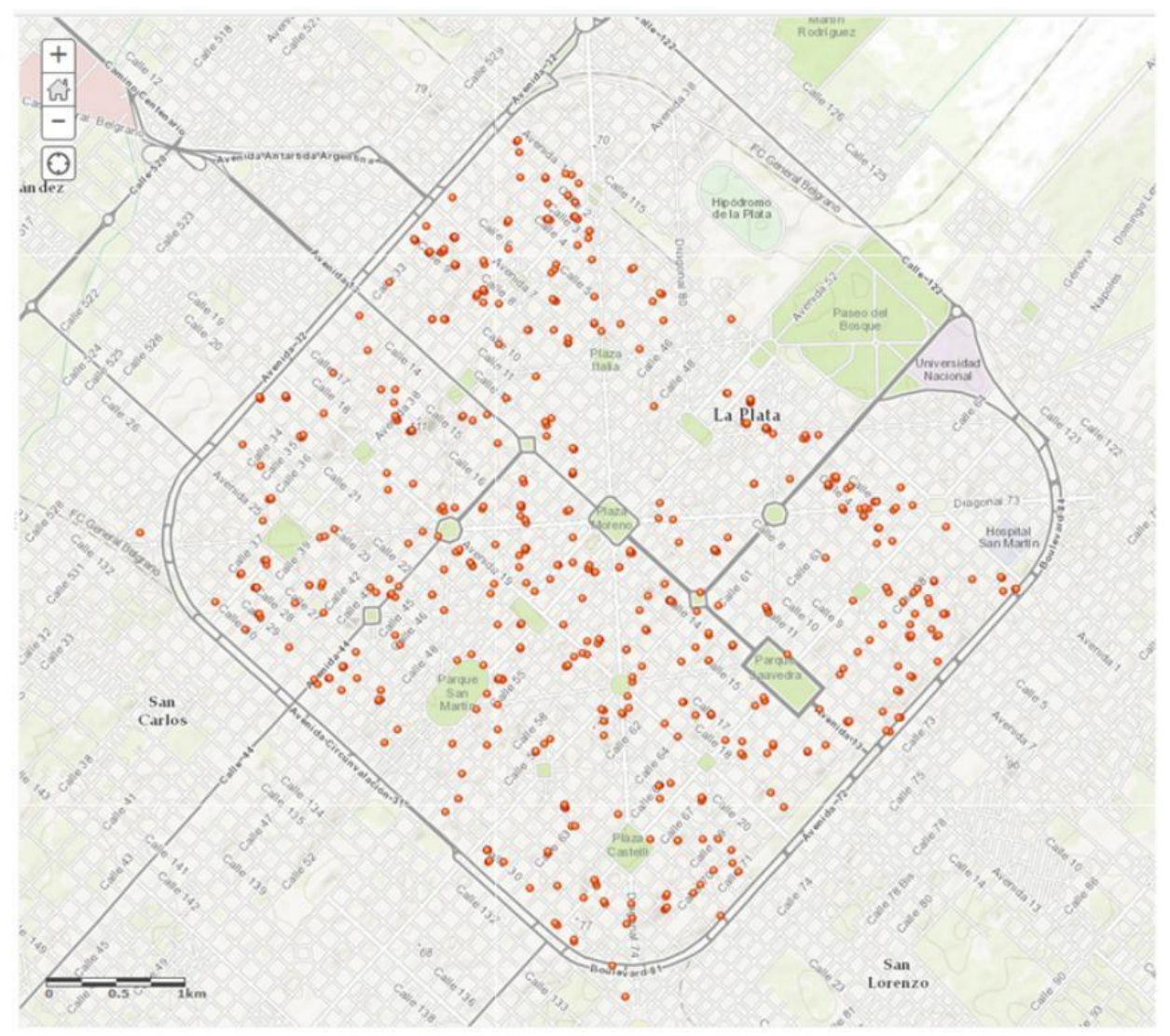

Notes: based on single occupancy houses for sale (data source: SIOC).

\section{IV.2. Noise Pollution}

The noise map was created by the Laboratory of Acoustics and Lighting belonging to the Commission for Scientific Research of the Province of Buenos Aires (LAL-CIC-PBA). For the construction of the noise map 146 measurement locations were used to form a grid that covers all the urban area of the city with 1.5 blocks resolution, i.e. the maximum distance to measurement locations is less than 150 meters. In Figure 2 distribution of the measuring points are shown. Noise measurements were took between August and November of 2013. Each measurement was performed on the sidewalk, in the intersection of two streets during rush hours (i.e. from 11:30 AM to 1:30 PM) on normal working days. The samples were taken during a period time of 15 minutes under good weather conditions: no rain and winds below 5 meters per second, equivalent to a gentle breeze. 
Figure 2: Spatial distribution of measurement locations

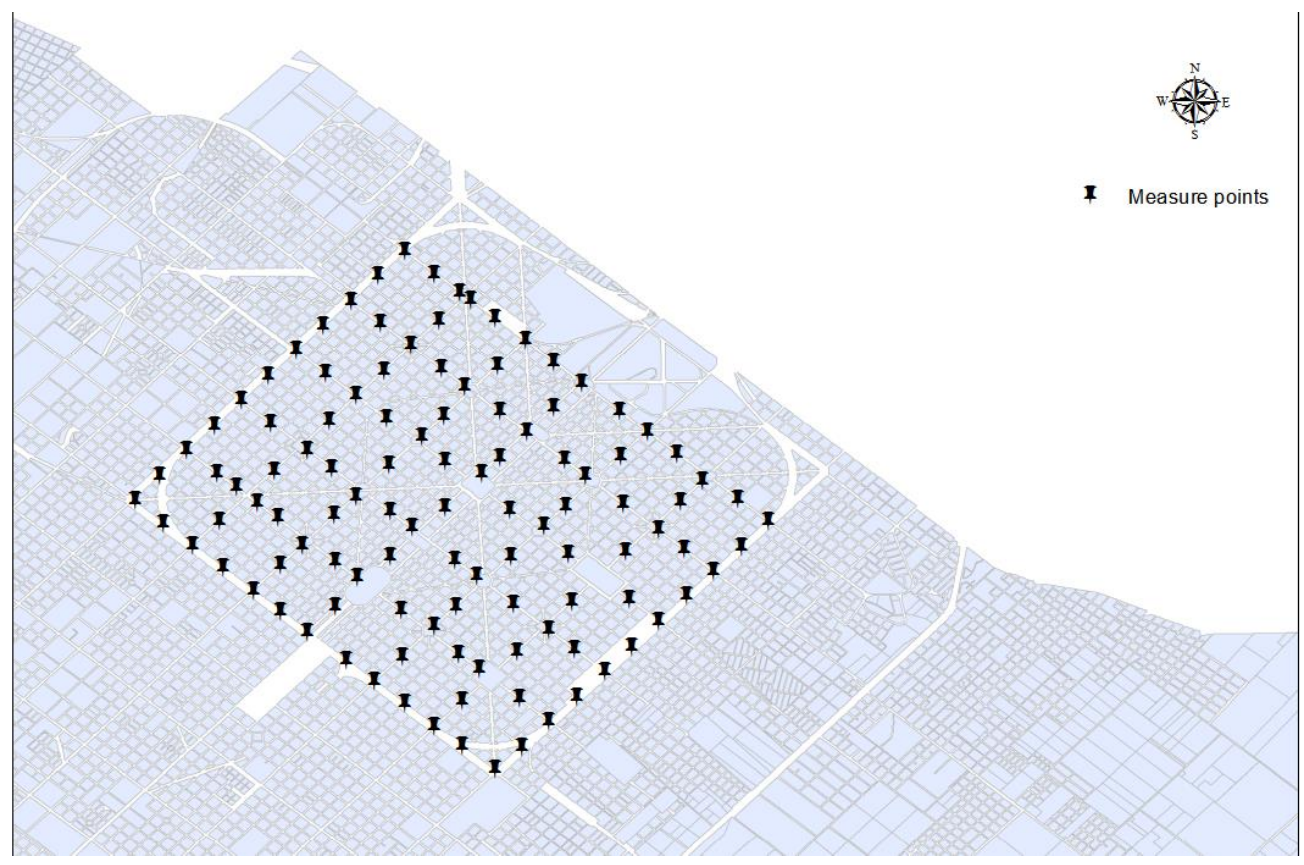

There are several ways to measure the noise level at any given location because the sound is not constant over time. Besides the most common Noise Pollution Level indicator in decibels, there are several other indicators such as the day-evening-night noise indicator for overall annoyance or the evening-noise indicator for sleep disturbance. Also, the Percentile levels Ln, where $\mathrm{n}$ may be anything from 1 to 99, is that noise level exceeded for $n \%$ of the measurement time. 10 It is often the case that only a few Ln values are ever used. For instance, L90 is frequently taken as the background level. L10-L90 is often used to give a quantitative measure as to the spread or "how choppy" the sound was. L10 is the noise level exceeded for $10 \%$ of the time of the measurement duration. This is often used to give an indication of the upper limit of fluctuating noise, such as that from road traffic. In addition to the indicators mentioned above there is the level equivalent of noise. The noise measure used in this work is the equivalent continuous sound level (LEQ), provided by LAL-CIC-PBA, and defined as the constant sound level throughout a period of time. ${ }^{11}$

The empirical analysis is based on houses for sale; consequently, there is a small gap between the spatial support of the noise data collected by a finite set of monitoring stations and the support of the property price for sale. There are several techniques to produce surfaces maps from point values for non-sampled (see Diem, 2003). These

\footnotetext{
${ }^{10}$ By definition of percentiles, $L 1$ must be greater than or equal to $L 2$, which must be greater than or equal to L3, and so on.

${ }^{11}$ Equivalent continuous sound level can be defined as continuous sound level that provides the same amount of energy as the weighted acoustic sound $(A)$ for a period of time $T$.

$$
L_{A E Q, T}=10 \cdot \log \frac{1}{T}\left(P a(t) / P_{0}\right)^{2} d t
$$

where $\mathrm{T}$ is the measurement time, $\mathrm{Pa}(\mathrm{t})$ is the instantaneous value of the sound pressure and $P_{0}$ is the reference sound pressure $(20 \mu \mathrm{Pa})$.
} 
surface generation techniques includes inverse distance weighting, kriging (ordinary kriging, universal kriging or co-kriging), and regression analysis. ${ }^{12}$ In this paper noise pollution for the location of each house was obtained using ordinary kriging. It is important to note that, given the spatial distribution of measuring points, the choice of interpolation method does not generate large changes in the results. Figure 3 shows the interpolated levels of noise; the darker red colour represents the highest noise levels. On average, the noise level is around 71 decibels (dB) when the World Health Organization recommends maximum levels between 60 and 65 decibels in outdoor spaces. The observation of the noise map suggests that avenues are among the noisiest axes of the city with more than 75 decibels.

Figure 3: Noise pollution interpolation

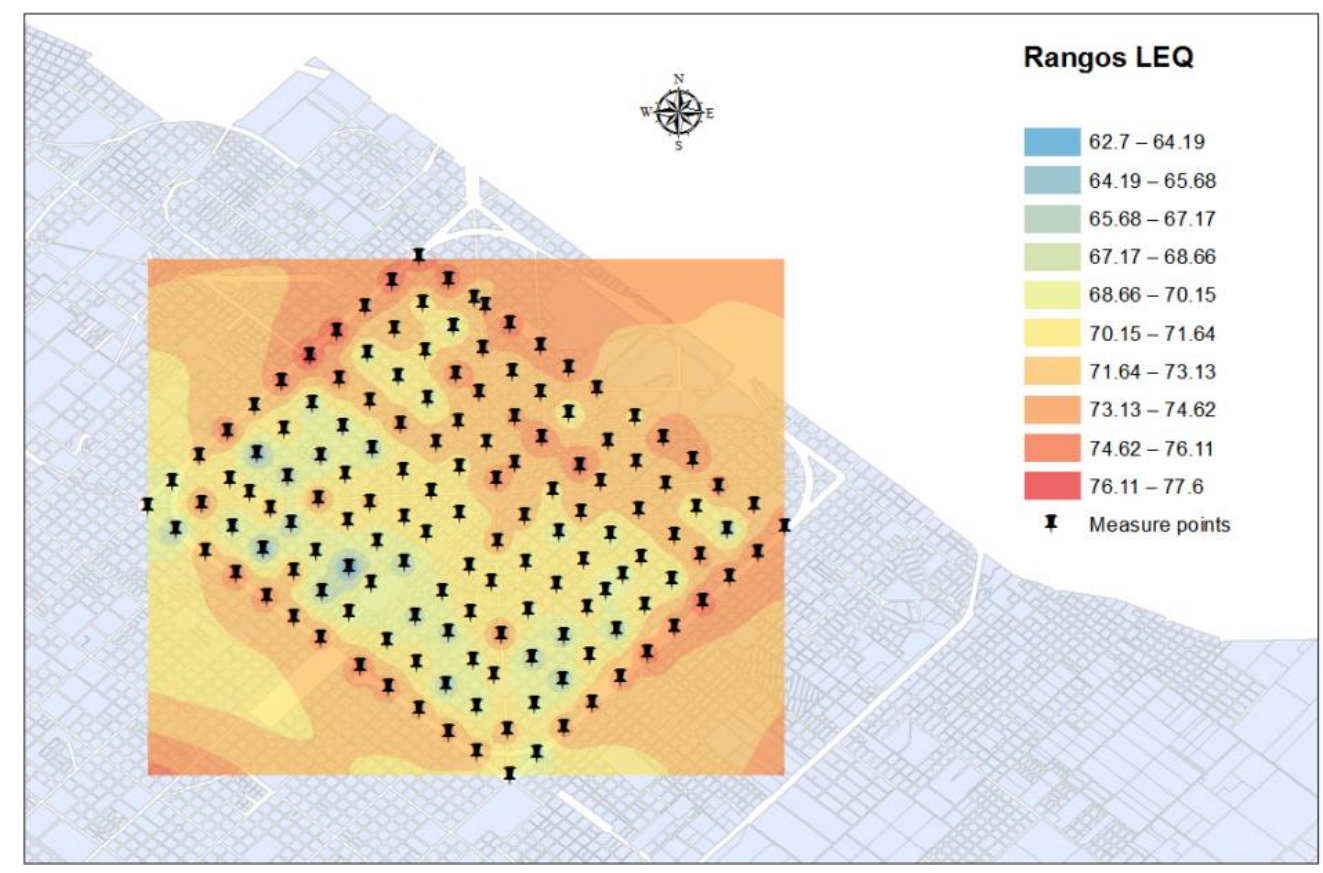

Notes: authors' own calculations

Although there is a time mismatch between the data of the properties for sale and noise, there have not been major changes in the main determinants of noise. The routes of urban public transport, pedestrian areas and the main accesses to the city remain the same. Consequently, results should be interpreted as a lower bound, since individuals may have upgraded their valuation of noise from 2010 to 2013. Unfortunately, there is not reliable data available about real estate offers for the period when the noise measurements were taken.

\footnotetext{
${ }^{12}$ For more details on interpolation methods see Anselin and Le Gallo (2006).
} 


\section{Results}

In this paper we estimate spatial hedonic price models to find out whether or not the housing market discounts noise pollution. The results of how noise affects housing prices in the city of La Plata are shown in Table 3.

In all specifications the dependent variable is the natural logarithm of houses price. The first five columns are the OLS estimates with different controls, while the remaining columns shown the results from spatial models estimated by the Generalized Method of Moments (GMM). ${ }^{13}$

Higher levels of noise surrounding a house negatively affect its price in all specifications. In particular, the OLS estimates (columns 1-5) show a statistically significant discount in the price of about $2.1 \%$ percent per additional decibel. Spatial models (columns 6-10) confirms this findings, however, the price discount is slightly lower, about $1.9 \%$ for each additional decibel.

A couple of points are worth mentioning. Firstly, estimated coefficients for noise pollution are very stable to the inclusion of different controls and to alternative estimation methods. Secondly, these estimates suggest that it would be beneficial to reduce noise pollution. Thirdly, the estimated impacts reported are in line with values found in the literature described in the second section. Fourthly, the estimated coefficient could overestimate the effect of noise, because this variable could be also picking up the effect of traffic congestion and limited parking space in the area, which would also tend to reduce house prices. Lastly, as with other estimates for environmental amenities, it is important to keep in mind that the estimated effect corresponds to a marginal change in noise pollution, and should not be expected to remain unchanged for non-marginal changes to noise exposure. A non-marginal change is likely to change the willingness to pay of individuals for a reduction in noise pollution and possibly induce a new balance of housing prices which has to be recalculated (Kim et al., 2003).

The other characteristics of the houses have the expected sign, the price increases as the surface of the lot and size of the constructed building increases. Similarly, houses with more bedrooms, bathrooms, garage and stories tend to have higher valuations. The relationship between the age and the price seem to be non-significant. After controlling for noise pollution, houses located on avenues have no significant effect and the ones located on floodplains have a significant discount on their prices. This last effect was also shown by Rabassa and Zoloa (2016). The distance to the business centre is positive and significant. Finally, the socioeconomic characteristics of the area, such as household income and the unemployment rate potentially correlated with the attributes of neighbours, have the expected effect on property prices. The $\lambda$ coefficient, which measures the spatial disturbance autoregressive structure, has a significant value of about 0.6 implying that a price shock will be transmitted throughout space.

\footnotetext{
${ }^{13}$ In order to take into account for heteroskedasticity in spatial models we use the heteroskedasticity autocorrelation consistent estimator (HAC) developed by Kelejian and Prucha (2007).
} 
Table 3: Estimated regressions

\begin{tabular}{|c|c|c|c|c|c|c|c|c|c|c|}
\hline \multirow[t]{2}{*}{ Variables } & \multicolumn{5}{|c|}{ OLS } & \multicolumn{5}{|c|}{ GMM } \\
\hline & (1) & (2) & (3) & (4) & (5) & (6) & (7) & (8) & (9) & (10) \\
\hline Noise (LEQ) & $-0.0246 * * *$ & $-0.0198 * * *$ & $-0.0214 * * *$ & $-0.0199 * * *$ & $-0.0192 * * *$ & $-0.0221 * *$ & $-0.0194 * *$ & $-0.0205^{* *}$ & $-0.0186 * *$ & $-0.0188^{* *}$ \\
\hline Currency (=1 US dollars) & $0.2539 * * *$ & $0.2449 * * *$ & $0.2542 * * *$ & $0.2515^{* * *}$ & $0.2495 * * *$ & $0.2166 * * *$ & $0.2100 * * *$ & $0.2187 * * *$ & $0.2128 * * *$ & $0.2133 * * *$ \\
\hline Log of lot size & $0.3007 * * *$ & $0.3061 * * *$ & $0.2991 * * *$ & $0.3096 * * *$ & $0.3056 * * *$ & $0.2937 * * *$ & $0.2997 * * *$ & $0.2996 * * *$ & $0.3020 * * *$ & $0.3027 * * *$ \\
\hline Log of house size & $0.2825 * * *$ & $0.2651 * * *$ & $0.2758^{* * *}$ & $0.2634 * * *$ & $0.2647 * * *$ & $0.3332 * * *$ & $0.3207 * * *$ & $0.3212 * * *$ & $0.3150 * * *$ & $0.3147 * * *$ \\
\hline Stories (number) & $0.1032 * * *$ & $0.1069 * * *$ & $0.1004 * * *$ & $0.1059 * * *$ & $0.1044 * * *$ & $0.0957 * * *$ & $0.0991 * * *$ & $0.0959 * * *$ & $0.0982 * * *$ & $0.0984 * * *$ \\
\hline Bedrooms (number) & 0.0202 & $0.0245 *$ & $0.0227 *$ & $0.0230 *$ & $0.0243 *$ & $0.0386 * *$ & $0.0412^{* *}$ & $0.0413 * *$ & $0.0431 * *$ & $0.0426 * *$ \\
\hline Baths (number) & $0.0515^{* * *}$ & $0.0507 * * *$ & $0.0521 * * *$ & $0.0500 * * *$ & $0.0509 * * *$ & $0.0351 * * *$ & $0.0323 * *$ & $0.0346 * * *$ & $0.0327 * *$ & $0.0326 * *$ \\
\hline House age (years) & -0.0009 & -0.0009 & -0.0008 & -0.0009 & -0.0009 & 0.0001 & -0.0001 & -0.0000 & -0.0001 & -0.0001 \\
\hline Garages (number) & $0.0609 * * *$ & $0.0567 * *$ & $0.0582 * *$ & $0.0571 * *$ & $0.0564 * *$ & $0.0595 * *$ & $0.0584 * *$ & $0.0594 * *$ & $0.0583 * *$ & $0.0586 * *$ \\
\hline Condition: good (=1 yes) & $0.0941 * * *$ & $0.0988 * * *$ & $0.0938^{* * *}$ & $0.0973 * * *$ & $0.0971 * * *$ & $0.1367 * * *$ & $0.1378 * * *$ & $0.1345^{* * *}$ & $0.1360 * * *$ & $0.1360 * * *$ \\
\hline Condition: excellent ( $=1$ yes) & $0.2033^{* * *}$ & $0.2028 * * *$ & $0.2031 * * *$ & $0.2081^{* * *}$ & $0.2049 * * *$ & $0.2247 * * *$ & $0.2271 * * *$ & $0.2244 * * *$ & $0.2257 * * *$ & $0.2263 * * *$ \\
\hline Time 2 (May) & $0.0808^{* * *}$ & $0.0861 * * *$ & $0.0842 * * *$ & $0.0854 * * *$ & $0.0864 * * *$ & $0.0690 * * *$ & $0.0709 * * *$ & $0.0705^{* * *}$ & $0.0716 * * *$ & $0.0716 * * *$ \\
\hline Time 3 (September) & $0.1435^{* * *}$ & $0.1484 * * *$ & $0.1459 * * *$ & $0.1502 * * *$ & $0.1493 * * *$ & $0.1156 * * *$ & $0.1193 * * *$ & $0.1185^{* * *}$ & $0.1204 * * *$ & $0.1206 * * *$ \\
\hline Distance to CBD $(\mathrm{km})$ & $-0.0949 * * *$ & $-0.0770 * * *$ & $-0.0826 * * *$ & $-0.0648 * * *$ & $-0.0699 * * *$ & $-0.0881 * * *$ & $-0.0625 * * *$ & $-0.0738 * * *$ & $-0.0601 * * *$ & $-0.0581 * * *$ \\
\hline Distance to CBD (Minutes) & 0.0146 & 0.0205 & 0.0115 & 0.0165 & 0.0162 & 0.0265 & 0.0322 & 0.0281 & 0.0322 & 0.0320 \\
\hline On avenue & & $0.0012 * * *$ & & $0.0008^{* *}$ & $0.0008^{* *}$ & & $0.0014 * * *$ & & $0.0010 * *$ & $0.0010 * *$ \\
\hline \multicolumn{11}{|l|}{ Average hourly wage } \\
\hline Unemployment rate & & 0.1902 & 0.1220 & & 0.1371 & & -0.0307 & -0.0374 & & -0.0512 \\
\hline Proportion of home and Land owners & & & $-0.8585 * * *$ & $-0.7436 * * *$ & $-0.7099 * * *$ & & & $-0.7746 * *$ & $-0.5810 *$ & $-0.5888 *$ \\
\hline Flooding risk: high & $-0.0697 * *$ & $-0.0665^{* *}$ & $-0.0532 *$ & $-0.0518^{*}$ & $-0.0533 *$ & $-0.1002 * *$ & $-0.0958 * *$ & $-0.0882 * *$ & $-0.0885^{*}$ & $-0.0878 *$ \\
\hline Flooding risk: moderate & $-0.0801 * * *$ & $-0.0705^{* * *}$ & $-0.0731 * * *$ & $-0.0710 * * *$ & $-0.0692 * * *$ & $-0.0525^{* *}$ & $-0.0450 *$ & $-0.0512 * *$ & $-0.0457 *$ & $-0.0458 *$ \\
\hline Constant & $9.8106^{* * *}$ & $8.6353 * * *$ & $9.6441 * * *$ & $9.1129 * * *$ & $8.9810 * * *$ & $9.3537 * * *$ & $8.3712 * * *$ & $9.3834 * * *$ & $8.5994 * * *$ & $8.6440 * * *$ \\
\hline Observations & 697 & 697 & 697 & 697 & 697 & 697 & 697 & 697 & 697 & 697 \\
\hline R-squared / Squared correlation & 0.843 & 0.847 & 0.848 & 0.849 & 0.849 & 0.838 & 0.840 & 0.842 & 0.843 & 0.843 \\
\hline Lambda & & & & & & $0.639 * * *$ & $0.635 * * *$ & $0.623 * * *$ & $0.629 * * *$ & $0.626 * * *$ \\
\hline
\end{tabular}

${ }^{*}$ significant at $10 \% ;{ }^{* *}$ significant at $5 \% ;{ }^{* *}$ significant at $1 \%$ 


\section{Sensivity Analysis}

As mentioned before, the noise map used in this paper was developed using data from the Laboratory of Acoustics and Lighting of the Committee for Scientific Research of the Province of Buenos Aires (LAL-CIC-PBA). In the construction of the map 146 sampling points were used, covering the city with a grid of $1.5 \times 1.5$ block resolution, i.e. the maximum distance from a house to a noise measurement point is less than 150 meters. This is one of the highest resolutions with which one could work. However, it might not be always possible to work such resolution, mainly due to the associated costs of measuring noise at many locations.

This section attempts to analyse the trade off, both financial and in terms of accuracy, of constructing a noise map based on fewer measurement locations. This is a valid question that policymakers must face when deciding to measure noise levels to produce a noise map.

For this purpose we compare the estimated impacts of noise on house prices from alternative noise maps. One option is to use a random sample of the actual measuring locations. However, it would not be reasonable for the authorities. Therefore, four scenarios are proposed. The first scenario contains 73 measuring points uniformly distributed across the city, which results in a grid with a resolution approximately two times larger than the one shown in Figure 2. Figure A1 (see the Appendix) shows the resulting measuring locations distribution. Under this scenario the total cost of measuring noise would be just half of the costs to produce the original map, assuming a constant cost per location. The second alternative contains only 40 measuring locations uniformly distributed throughout the area, which results in grid with an approximate resolution of $5 \times 5$ blocks. The map in Figure A2 shows the resulting sampling location distribution. This scenario would represent around $34 \%$ of the cost of producing of the original map from 146 measuring locations, assuming a constant cost per measurement unit. In the third scenario the measuring locations are located at the intersections of the main avenues, where noise from traffic is higher. This scenario would have 43 measurement locations, which results in a grid with a resolution of approximately $5 \times 5$ blocks and about $29 \%$ of the cost of producing the original map. Figure A3 shows the measuring locations distribution under this scenario. The final scenario considers measuring noise from those locations over avenues. This scenario would have 113 measurement locations, which results in a resolution of approximately $2 \times 2$ blocks. The map in Figure A4 shows the location distribution. This scenario would represent $77 \%$ of the cost of producing the original map.

The way in which the differences between scenarios are analysed involves the selection of 5000 randomly distributed points in each noise map and then comparing these results with those from the original map. The first scenario shows an underestimation of approximately $-0.30 \%$, with differences ranging from $-7.5 \%$ to $11.10 \%$. Half of the differences is between $-1.3 \%$ (25th percentile) and $0.5 \%$ (75th percentile), as shown in Table 4. In the second scenario there is an overestimation of approximately $1.3 \%$, with values ranging from $6.5 \%$ to $12.7 \%$, whereas $50 \%$ of the differences are between $0.1 \%$ and $2.40 \%$. While in the third scenario an overestimation of about $1 \%$ is found, 
with values ranging from $-6.6 \%$ to $12.50 \%$, whereas $50 \%$ of the differences occur between $-0.2 \%$ and $1.9 \%$. Finally, in the fourth scenario an overestimation of about $0.6 \%$, is observed with values ranging from $-7.2 \%$ to $10.3 \%$. In this case, $50 \%$ of the differences are between $0 \%$ and $0.9 \%$.

Table 4: Descriptive statistics

\begin{tabular}{lcccc}
\hline Statistic & \multicolumn{4}{c}{ Scenario } \\
\cline { 2 - 5 } & 1 & 2 & 3 & 4 \\
\hline Mean & $-0.30 \%$ & $1.30 \%$ & $1.00 \%$ & $0.60 \%$ \\
Standard deviation & $1.70 \%$ & $2.10 \%$ & $1.90 \%$ & $1.40 \%$ \\
Minimum & $-7.50 \%$ & $-6.50 \%$ & $-6.60 \%$ & $-7.20 \%$ \\
Percentile 1 & $-4.90 \%$ & $-3.20 \%$ & $-3.30 \%$ & $-2.70 \%$ \\
Percentile 5 & $-3.00 \%$ & $-1.90 \%$ & $-1.90 \%$ & $-0.70 \%$ \\
Percentile 10 & $-2.20 \%$ & $-1.20 \%$ & $-1.40 \%$ & $-0.30 \%$ \\
Percentile 25 & $-1.30 \%$ & $0.10 \%$ & $-0.20 \%$ & $0.00 \%$ \\
Median & $-0.20 \%$ & $1.30 \%$ & $1.00 \%$ & $0.40 \%$ \\
Percentile 75 & $0.50 \%$ & $2.40 \%$ & $1.90 \%$ & $0.90 \%$ \\
Percentile 90 & $1.30 \%$ & $3.80 \%$ & $3.10 \%$ & $1.90 \%$ \\
Percentile 95 & $2.00 \%$ & $4.70 \%$ & $4.20 \%$ & $3.00 \%$ \\
Percentile 99 & $4.50 \%$ & $7.90 \%$ & $7.20 \%$ & $6.40 \%$ \\
Maximum & $11.10 \%$ & $12.70 \%$ & $12.50 \%$ & $10.30 \%$ \\
Measuring points & 73 & 40 & 43 & 113 \\
Relative cost & $50.00 \%$ & $27.40 \%$ & $29.50 \%$ & $77.40 \%$ \\
\hline
\end{tabular}

Another interesting question is how the results would be in terms of the marginal willingness to pay for reducing noise pollution if the map made in each scenario is used instead of the LAL-CICBA map. Tables A1, A2, A3 and A4 show the estimates results using the noise maps of the scenario $1,2,3$, and 4 , respectively.

Overall these results show that there is no large loss in efficiency if fewer measurement locations are used to elaborate the noise map if the measuring locations are carefully selected. However, this result depends on the purpose of the study. As expected, the larger errors correspond to areas that are more distant from the measuring locations and especially in areas between avenues in the last scenario. If these areas are relevant for the analysis the loss of efficiency could be a serious issue.

\section{Conclusions}

Most of the world's population currently resides in cities. By 2050 over two-thirds of the world will live in urban areas, and much of this transition will occur in developingcountry cities with populations of at least 1 million (Christiaensen and Kanbur 2017; UN 2018). The urban landscape is undergoing unprecedented shifts, with rising populations and accelerating economic activity. As they grow more cities are affected by high levels of air and noise pollution arising mainly from traffic and industrial activities. Noise is an environmental stress factor that can cause disorders in sleep and 
learning, memory, motivation, problem solving and also increase irritability and aggressiveness making difficult to make cities and human settlements inclusive, safe, resilient and sustainable.

An accurate assessment of the benefits associated with reduced levels of noise pollution is especially relevant in the design of mitigation policies, as it determines whether the benefits of these policies exceed the costs associated with their implementation, such as the selection of asphalt layers or redesigning the public transport network. We considered that this study might have important implications in the policy-decision making process about future investments in infrastructure.

The willingness to pay to reduce noise has been estimated from spatial hedonic models using a high resolution noise map produced from a densely measurement network. The results suggest that when a house is located in a noisier area it suffers a reduction in its price. This discount is approximately $1.9 \%$ per additional decibel. The estimated willingness to pay needs to be confronted with the expected costs of the different environmental control projects in order to prioritize investments.

In addition, this paper present sensitivity analyses which allow us to know the effect in terms of costs and accuracy of working with a less dense measuring network. This is a major issue for public official that are considering the construction of such maps. Results from these sensitivity analysis show that there is not much loss of efficiency if the analysis is perform with fewer measurement locations, as long as the measuring locations are carefully selected. 


\section{References}

Angeletti, K. (2000). Valuación de la contaminación del aire y del ruido por el método de los precios hedónicos: una aplicación a la ciudad de La Plata (Tesis de Maestría en Finanzas Públicas Provinciales y Municipales). Universidad Nacional de La Plata. Facultad de Ciencias Económicas.

Anselin, L. (1988). Spatial Econometrics: Method and Models. Dordrecht: Kluwer Academic Publishers.

Anselin, L. (2005). Exploring spatial data with geoda: A workbook. Department of Geography, University of Illinois, Urbana-Champaign.

Anselin, L. \& Le Gallo, J. (2006). "Interpolation of air quality measures in hedonic house price models: Spatial aspects". Spatial Economic Analysis, 1(1), 31-52.

Bateman, I., Day, B., Lake, I., \& Lovett, A. (2000). The effect of road traffic on residential property values: A literature review and hedonic pricing study. Report to The Scottish Office, Development Department, Edinburgh, School of Environmental Sciences, University of East Anglia, Norwich.

Bertrand, N. F. (1997). Meta-analysis of studies of willingness to pay to reduce traffic noise. MSc dissertation, University College London.

Case, K. \& Shiller, R. (2003). "Is there a bubble in the housing market?". Brookings Papers on Economic Activity, 2, 299-362.

Christiaensen, L. \& Kanbur, R. (2017). "Secondary towns and poverty reduction: Refocusing the urbanization agenda." Annual Review of Resource Economics. 9, 405419.

Conte Grand, M. (2001). Una primera aproximación a la valuación hedónica de la contaminación en Buenos Aires. Serie Documentos de Trabajo No. 207. Universidad del CEMA.

Day, B. (2001). The theory of hedonic markets: Obtaining welfare measures for changes in environmental quality using hedonic market data. Economics for the Environment Consultancy (Eftec), London.

Diem, J. (2003). "A critical examination of ozone mapping from a spatial-scale perspective". Environmental pollution, 125(3), 369-383.

Harrison, D. \& Rubinfeld, D. (1978). "Hedonic housing prices and the demand for clean air". Journal of environmental economics and management, 5(1), 81-102.

Hawkins, R. (1999). Review of studies on external costs of noise. prepared. Environment Protection Economics Division, DETR (DEFRA).

Herrera, M. (2015). Econometría espacial usando stata. Breve guía aplicada para datos de corte transversal. Documentos de Trabajo del IELDE, (13). Documento Técnico No 1 . 
Hurtado, M., Giménez, J., Cabral, M., Silva, M., Martinez, O., Camilion, M., Sanchez, C., Gebhard, J., Forte, L., Boff, L., Crincoli, A., \& Lucesoli, H. (2006). Análisis ambiental del partido de La Plata: Aportes al ordenamiento territorial. Consejo Federal de Inversiones, Facultad de Ciencias Naturales y Museo, La Plata.

Kelejian, H. \& Prucha, I. (2007). "Hac estimation in a spatial framework". Journal of Econometrics, 140, 131-154.

Kim, C., Phipps, T., \& Anselin, L. (2003). "Measuring the benefits of air quality improvement: a spatial hedonic approach". Journal of environmental economics and management, 45(1), 24-39.

LeSage, J. \& Pace, K. (2009). Introduction to spatial econometrics. Chapman and Hall/CRC editor; First Edition.

Navrud, S. (2002). The state of the art on economic valuation of noise. Final Report to European Commission DG Environment.

Nelson, J. (2004). "Meta-analysis of airport noise and hedonic property values". Journal of Transport Economics and Policy, 38(1), 1-27.

Rabassa. M. \& Zoloa, J.I (2016). "Flood Risks and Housing Prices: A Spatial Hedonic Model for La Plata". Environment and Development Economics, 21(4), 464-489.

Ridker, R. \& Henning, J. (1967). "The determinants of residential property values with special reference to air pollution". The Review of Economics and Statistics, 49(2), 246257.

Rosen, S. (1974). "Hedonic prices and implicit markets: product differentiation in pure competition". Journal of Political Economy, 1(82), 34-55.

UN (2018). World Population Prospects. Department of Economic and Social Affairs Population Dynamics. United Nations. Available at https://population.un.org/wpp/

WHO (2011). Burden of disease from environmental noise. Quantification of healthy life years lost in Europe. World Health Organization (WHO).

Zoloa, J.I. (2015). Tópicos en el mercado inmobiliario: Un análisis desde la econometría espacial (Tesis de Doctorado en Economía).Universidad Nacional de La Plata, Facultad de Ciencias Económicas. 


\section{Appendix}

Figure A4: Noise map, scenario 1

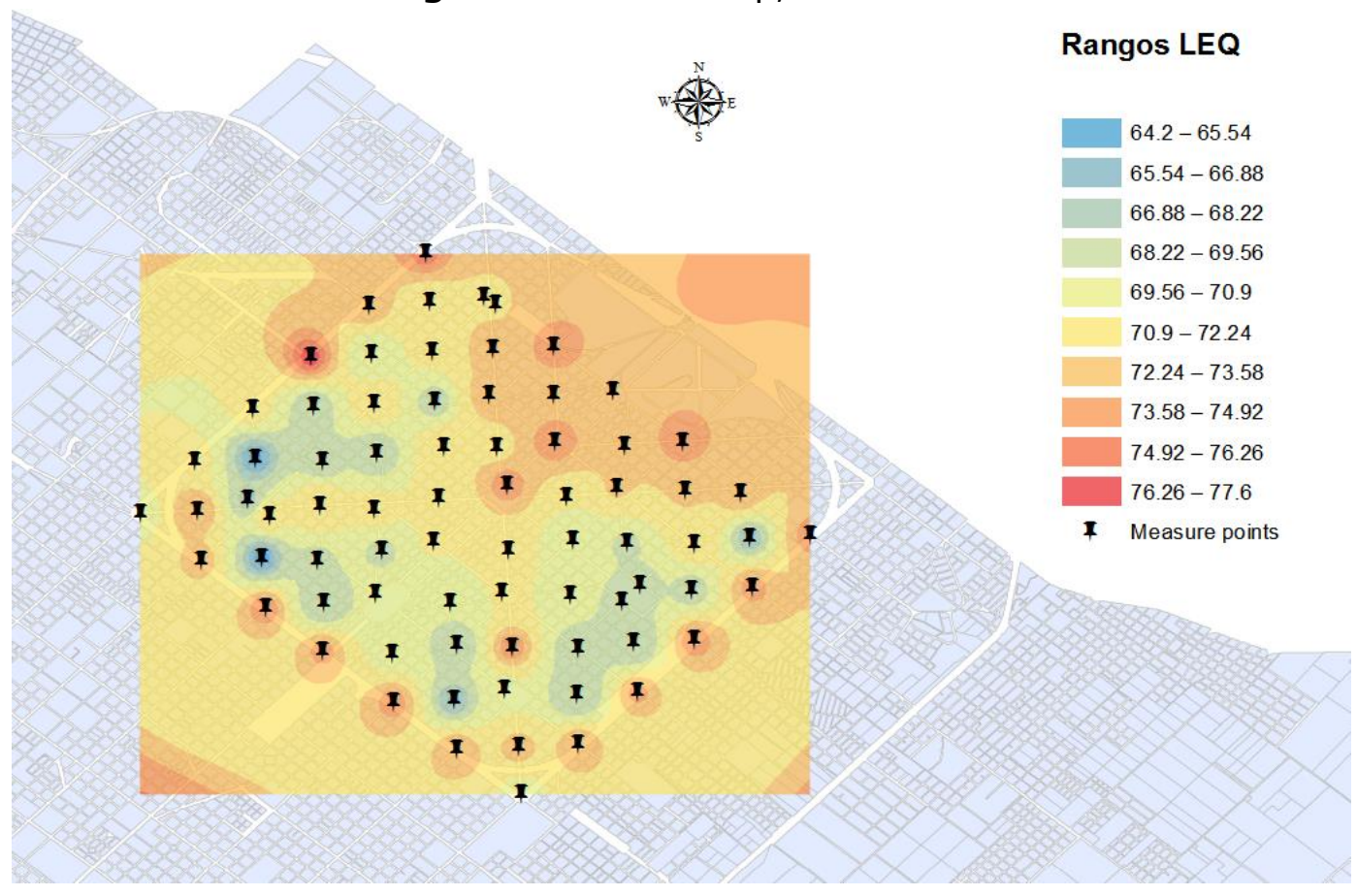

Figure A5: Noise map, scenario 2

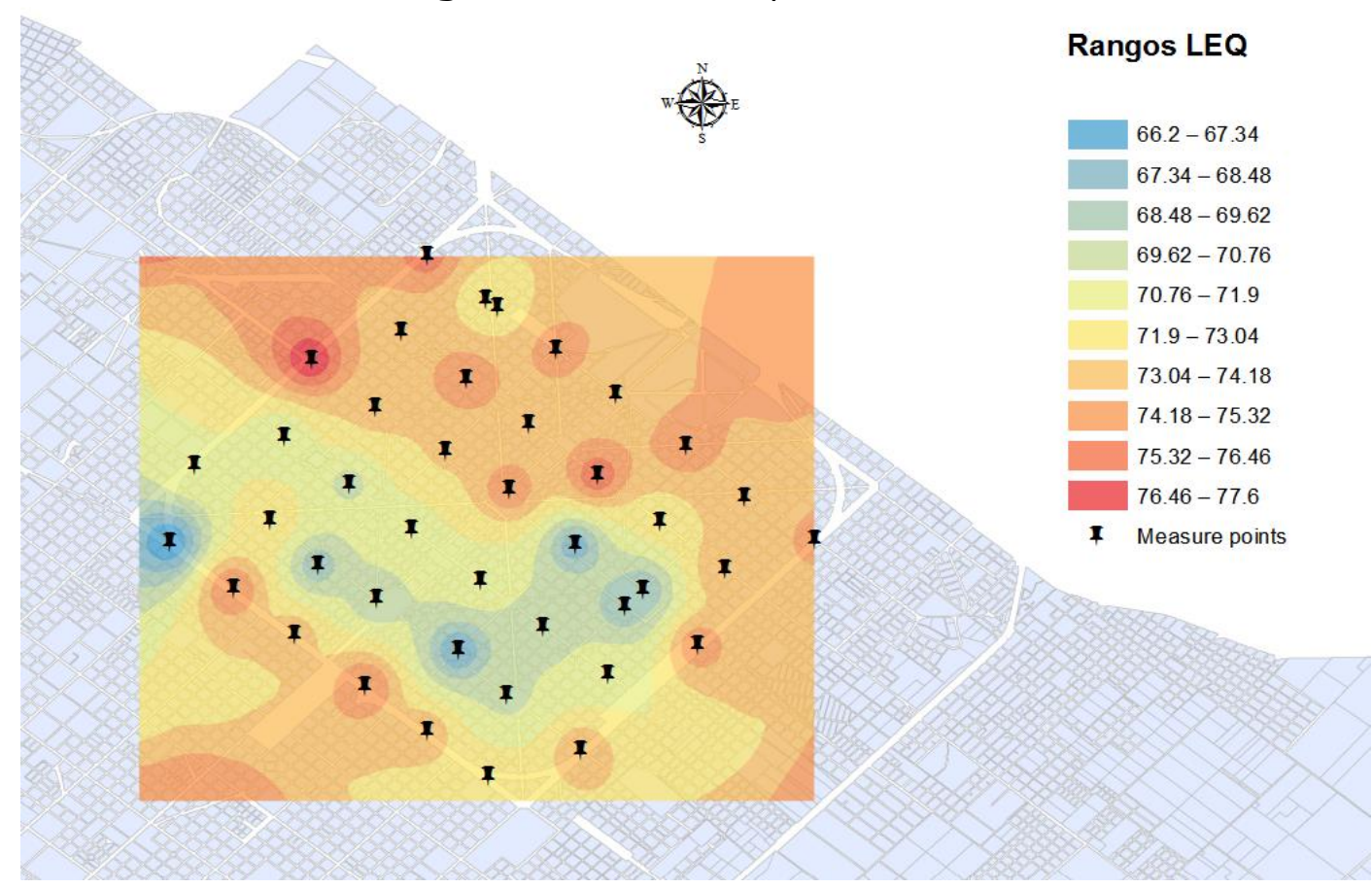


Figure A6: Noise map, scenario 3

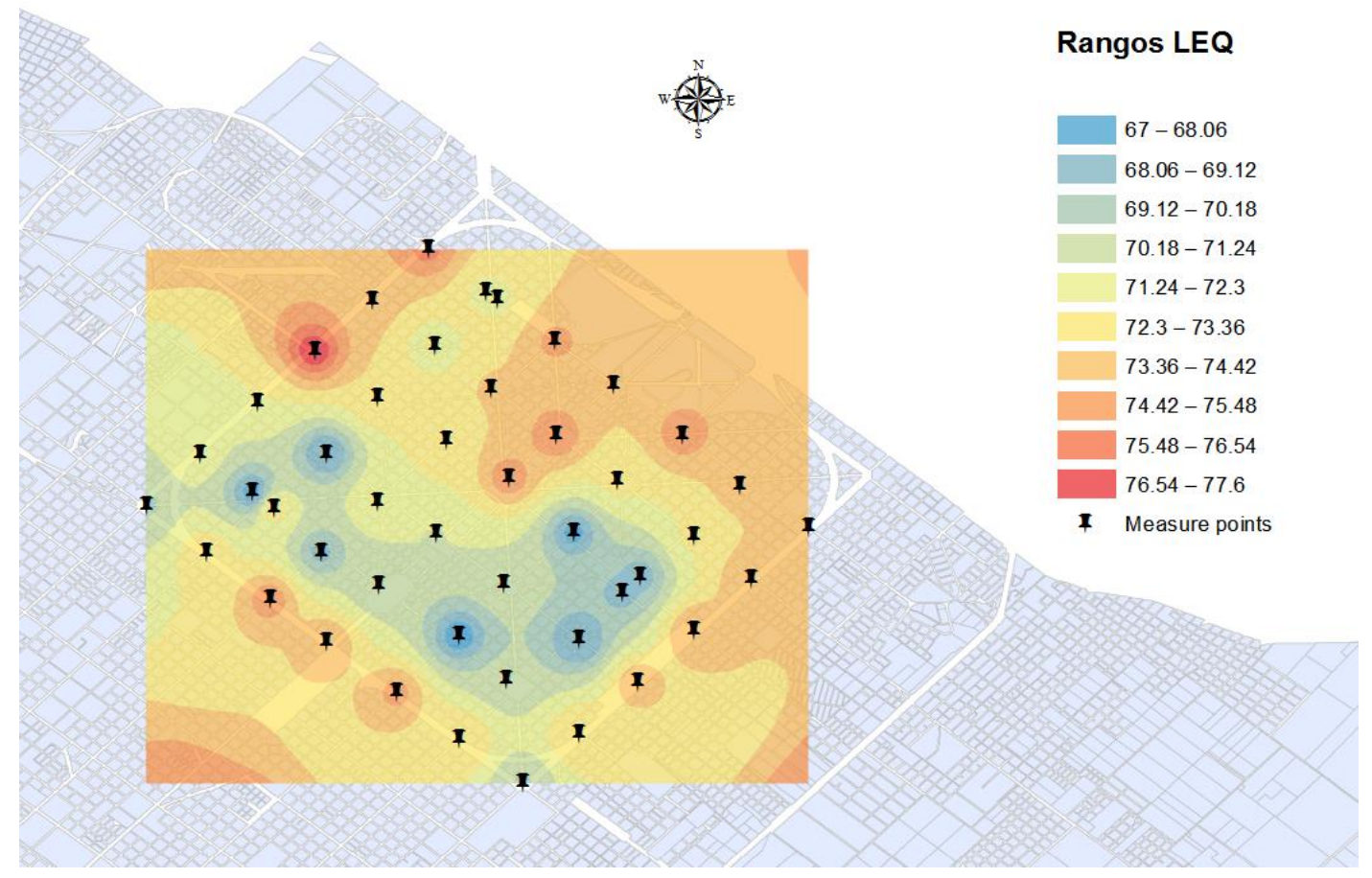

Figure A7: Noise map, scenario 4

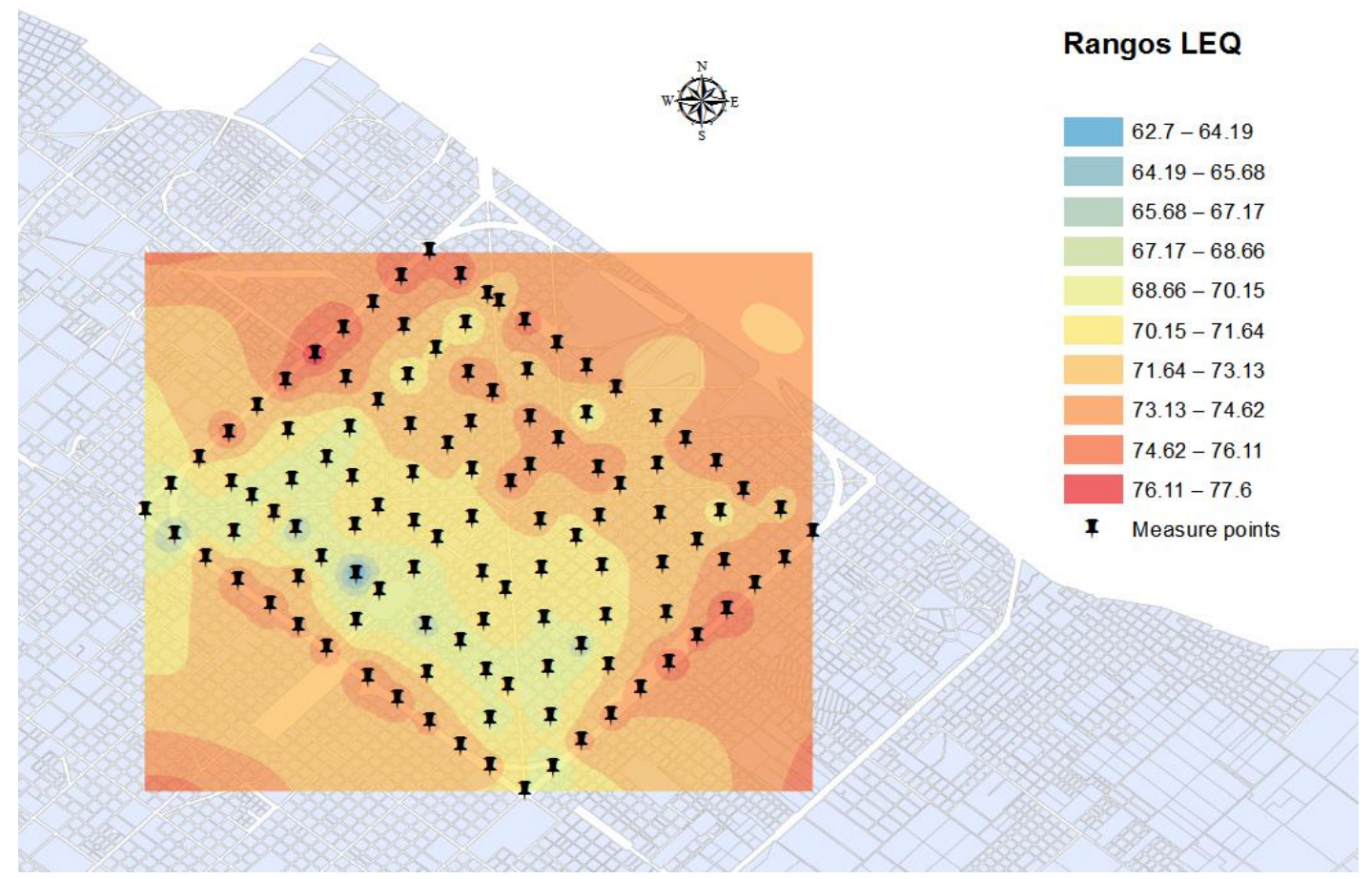


Table A1: Estimated impacts under scenario 1

\begin{tabular}{|c|c|c|c|c|c|c|c|c|c|c|}
\hline \multirow[t]{2}{*}{ Variables } & \multicolumn{5}{|c|}{ OLS } & \multicolumn{5}{|c|}{ GMM } \\
\hline & (1) & (2) & (3) & (4) & (5) & (6) & (7) & (8) & (9) & (10) \\
\hline Noise (LEQ) & $-0.0270 * * *$ & $-0.0222 * * *$ & $-0.0226 * * *$ & $-0.0217 * * *$ & $-0.0208^{* * *}$ & $-0.0221 * *$ & $-0.0199 * *$ & $-0.0199 * *$ & $-0.0182 *$ & $-0.0187 * *$ \\
\hline Currency (=1 US dollars) & $0.2631 * * *$ & $0.2528 * * *$ & $0.2625^{* * *}$ & $0.2586 * * *$ & $0.2568^{* * *}$ & $0.2224 * * *$ & $0.2153 * * *$ & $0.2241 * * *$ & $0.2176 * * *$ & $0.2182 * * *$ \\
\hline Log of lot size & $0.2984 * * *$ & $0.3054 * * *$ & $0.2978^{* * *}$ & $0.3080 * * *$ & $0.3048 * * *$ & $0.2917 * * *$ & $0.2983 * * *$ & $0.2977 * * *$ & $0.3002 * * *$ & $0.3011 * * *$ \\
\hline Log of house size & $0.2788 * * *$ & $0.2615^{* * *}$ & $0.2731 * * *$ & $0.2604 * * *$ & $0.2616 * * *$ & $0.3303 * * *$ & $0.3178 * * *$ & $0.3192 * * *$ & $0.3129 * * *$ & $0.3124 * * *$ \\
\hline Stories (number) & $0.0998 * * *$ & $0.1045 * * *$ & $0.0979 * * *$ & $0.1034 * * *$ & $0.1023 * * *$ & $0.0943 * * *$ & $0.0980 * * *$ & $0.0946 * * *$ & $0.0971 * * *$ & $0.0974 * * *$ \\
\hline Bedrooms (number) & $0.0244 *$ & $0.0277 * *$ & $0.0258 *$ & $0.0263 *$ & $0.0272 * *$ & $0.0395^{* *}$ & $0.0419 * *$ & $0.0419 * *$ & $0.0437 * *$ & $0.0432 * *$ \\
\hline Baths (number) & $0.0498 * * *$ & $0.0491 * * *$ & $0.0505^{* * *}$ & $0.0486 * * *$ & $0.0494 * * *$ & $0.0358 * * *$ & $0.0328 * *$ & $0.0351 * * *$ & $0.0332 * *$ & $0.0330 * *$ \\
\hline House age (years) & -0.0009 & -0.0009 & -0.0008 & -0.0009 & -0.0009 & 0.0001 & -0.0001 & -0.0000 & -0.0001 & -0.0001 \\
\hline Garages (number) & $0.0581 * *$ & $0.0546 * *$ & $0.0558 * *$ & $0.0548 * *$ & $0.0543 * *$ & $0.0574 * *$ & $0.0567 * *$ & $0.0575^{* *}$ & $0.0564 * *$ & $0.0568 * *$ \\
\hline Condition: good (=1 yes) & $0.1010 * * *$ & $0.1045^{* * *}$ & $0.0997 * * *$ & $0.1030 * * *$ & $0.1026 * * *$ & $0.1397 * * *$ & $0.1407 * * *$ & $0.1373 * * *$ & $0.1386 * * *$ & $0.1387 * * *$ \\
\hline Condition: excellent (=1 yes) & $0.2114 * * *$ & $0.2101 * * *$ & $0.2109 * * *$ & $0.2146 * * *$ & $0.2119 * * *$ & $0.2279 * * *$ & $0.2303 * * *$ & $0.2278 * * *$ & $0.2287 * * *$ & $0.2295^{* * *}$ \\
\hline Time 2 (May) & $0.0819 * * *$ & $0.0869 * * *$ & $0.0849 * * *$ & $0.0863 * * *$ & $0.0871 * * *$ & $0.0698 * * *$ & $0.0716 * * *$ & $0.0711 * * *$ & $0.0723 * * *$ & $0.0722 * * *$ \\
\hline Time 3 (September) & $0.1456 * * *$ & $0.1504 * * *$ & $0.1477 * * *$ & $0.1519 * * *$ & $0.1511 * * *$ & $0.1173 * * *$ & $0.1209 * * *$ & $0.1199 * * *$ & $0.1217 * * *$ & $0.1220 * * *$ \\
\hline Distance to CBD $(\mathrm{km})$ & $-0.0959 * * *$ & $-0.0767 * * *$ & $-0.0824 * * *$ & $-0.0657 * * *$ & $-0.0695 * * *$ & $-0.0889 * * *$ & $-0.0626 * * *$ & $-0.0739 * * *$ & $-0.0605 * * *$ & $-0.0581 * * *$ \\
\hline Distance to CBD (Minutes) & 0.0197 & 0.0250 & 0.0155 & 0.0209 & 0.0203 & 0.0267 & 0.0326 & 0.0280 & 0.0324 & 0.0322 \\
\hline On avenue & & $0.0012 * * *$ & & $0.0008^{* *}$ & $0.0008^{* *}$ & & $0.0014 * * *$ & & $0.0010 * *$ & $0.0010 * *$ \\
\hline \multicolumn{11}{|l|}{ Average hourly wage } \\
\hline Unemployment rate & & 0.1571 & 0.0921 & & 0.1094 & & -0.0462 & 0.0513 & & -0.0647 \\
\hline Proportion of home and Land owners & & & $-0.8340 * * *$ & $-0.7056 * * *$ & $-0.6807 * * *$ & & & $-0.7577 * *$ & $-0.5595^{*}$ & $-0.5681 *$ \\
\hline Flooding risk: high & $-0.0713 * *$ & $-0.0675 * *$ & $-0.0547 *$ & $-0.0537 *$ & $-0.0548 *$ & $-0.0999 * *$ & $-0.0954 * *$ & $-0.0880 * *$ & $-0.0885 * *$ & $-0.0877^{*}$ \\
\hline Flooding risk: moderate & $-0.0920 * * *$ & $-0.0807 * * *$ & $-0.0836 * * *$ & $-0.0806 * * *$ & $-0.0788 * * *$ & $-0.0594 * *$ & $-0.0511 * *$ & $-0.0575 * *$ & $-0.0515^{* *}$ & $-0.0516 * *$ \\
\hline Constant & $9.9870 * * *$ & $8.8245^{* * *}$ & $9.7458 * * *$ & $9.2241 * * *$ & $9.0891 * * *$ & $9.3701 * * *$ & $8.4271 * * *$ & $9.3552 * * *$ & $8.5661 * * *$ & $8.6352 * * *$ \\
\hline Observations & 697 & 697 & 697 & 697 & 697 & 697 & 697 & 697 & 697 & 697 \\
\hline R-squared / Squared correlation & 0.844 & 0.847 & 0.849 & 0.849 & 0.850 & 0.844 & 0.839 & 0.841 & 0.843 & 0.843 \\
\hline Lambda & & & & & & $0.632 * * *$ & $0.629 * * *$ & $0.618^{* * *}$ & $0.623 * * *$ & $0.621 * * *$ \\
\hline
\end{tabular}

${ }^{*}$ significant at 10\%; ** significant at $5 \%$; ${ }^{* *}$ significant at $1 \%$ 
Table A2: Estimated impacts under scenario 2

\begin{tabular}{|c|c|c|c|c|c|c|c|c|c|c|}
\hline \multirow[t]{2}{*}{ Variables } & \multicolumn{5}{|c|}{ OLS } & \multicolumn{5}{|c|}{ GMM } \\
\hline & (1) & (2) & (3) & (4) & (5) & (6) & (7) & (8) & (9) & (10) \\
\hline Noise (LEQ) & $-0.0185^{* * *}$ & $-0.0138^{* *}$ & $-0.0146 * * *$ & $-0.0126 * *$ & $-0.0124 * *$ & $-0.0191^{*}$ & -0.0154 & $-0.0163^{*}$ & -0.0140 & -0.0142 \\
\hline Currency (=1 US dollars) & $0.2579 * * *$ & $0.2477 * * *$ & $0.2676 * * *$ & $0.2547 * * *$ & $0.2522 * * *$ & $0.2179 * * *$ & $0.2115^{* * *}$ & $0.2200 * * *$ & $0.2142 * * *$ & $0.2146 * * *$ \\
\hline Log of lot size & $0.2987 * * *$ & $0.3040 * * *$ & $0.2963 * * *$ & $0.3081 * * *$ & $0.3035 * * *$ & $0.2922 * * *$ & $0.2980 * * *$ & $0.2978 * * *$ & $0.3003^{* * *}$ & $0.3010 * * *$ \\
\hline Log of house size & $0.2832 * * *$ & $0.2659 * * *$ & $0.2777 * * *$ & $0.2647 * * *$ & $0.2660 * * *$ & $0.3311 * * *$ & $0.3198 * * *$ & $0.3204 * * *$ & $0.3147 * * *$ & $0.3144 * * *$ \\
\hline Stories (number) & $0.0998 * * *$ & $0.1042 * * *$ & $0.0974 * * *$ & $0.1038 * * *$ & $0.1020 * * *$ & $0.0947 * * *$ & $0.0982 * * *$ & $0.0949 * * *$ & $0.0973 * * *$ & $0.0975^{* * *}$ \\
\hline Bedrooms (number) & 0.0214 & $0.0257 *$ & $0.0238^{*}$ & $0.0237 *$ & $0.0252 *$ & $0.0391 * *$ & $0.0416 * *$ & $0.0417 * *$ & $0.0433^{* *}$ & $0.0429 * *$ \\
\hline Baths (number) & $0.0524 * * *$ & $0.0515^{* * *}$ & $0.0530 * * *$ & $0.0506 * * *$ & $0.0516 * * *$ & $0.0371 * * *$ & $0.0340 * *$ & $0.0364 * * *$ & $0.0343 * *$ & $0.0342 * *$ \\
\hline House age (years) & -0.0007 & -0.0008 & -0.0007 & -0.0008 & -0.0008 & 0.0001 & -0.0000 & 0.0000 & -0.0000 & -0.0000 \\
\hline Garages (number) & $0.0599 * * *$ & $0.0555^{* *}$ & $0.0569 * *$ & $0.0557 * *$ & $0.0550 * *$ & $0.0588 * *$ & $0.0575 * *$ & $0.0585^{* *}$ & $0.0573 * *$ & $0.0575^{* *}$ \\
\hline Condition: good (=1 yes) & $0.0991 * * *$ & $0.1027 * * *$ & $0.0978 * * *$ & $0.1011 * * *$ & $0.1007 * * *$ & $0.1400 * * *$ & $0.1403 * * *$ & $0.1373 * * *$ & $0.1384 * * *$ & $0.1383 * * *$ \\
\hline Condition: excellent (=1 yes) & $0.2121 * * *$ & $0.2094 * * *$ & $0.2102 * * *$ & $0.2153 * * *$ & $0.2113 * * *$ & $0.2271 * * *$ & $0.2291 * * *$ & $0.2266 * * *$ & $0.2279 * * *$ & $0.2284 * * *$ \\
\hline Time 2 (May) & $0.0803 * * *$ & $0.0860 * * *$ & $0.0839 * * *$ & $0.0852 * * *$ & $0.0864 * * *$ & $0.0698 * * *$ & $0.0705 * * *$ & $0.0700 * * *$ & $0.0712 * * *$ & $0.0711 * * *$ \\
\hline Time 3 (September) & $0.1435^{* * *}$ & $0.1484 * * *$ & $0.1456 * * *$ & $0.1503 * * *$ & $0.1492 * * *$ & $0.1156 * * *$ & $0.1192 * * *$ & $0.1182 * * *$ & $0.1201 * * *$ & $0.1203 * * *$ \\
\hline Distance to CBD $(\mathrm{km})$ & $-0.0884 * * *$ & $-0.0717 * * *$ & $-0.0777 * * *$ & $-0.0580 * * *$ & $-0.0643 * * *$ & $-0.0840 * * *$ & $-0.0591 * * *$ & $-0.0702 * * *$ & $-0.0563 * * *$ & $-0.0546 * * *$ \\
\hline Distance to CBD (Minutes) & 0.0056 & 0.0133 & 0.0034 & 0.0093 & 0.0092 & 0.0193 & $0.0014 * * *$ & 0.0216 & 0.0264 & 0.0261 \\
\hline On avenue & & $0.0013 * * *$ & & $0.0008^{* *}$ & $0.0009 * *$ & & $0.0014 * * *$ & & $0.0010 * *$ & $0.0010 * *$ \\
\hline \multicolumn{11}{|l|}{ Average hourly wage } \\
\hline Unemployment rate & & $0.2116 *$ & 0.1460 & & 0.1599 & & -0.0238 & -0.0292 & & -0.0431 \\
\hline Proportion of home and Land owners & & & $-0.8497 * * *$ & $-0.7340 * * *$ & $-0.6944 * * *$ & & & $-0.7606 * *$ & $-0.5705^{*}$ & $-0.5771 *$ \\
\hline Flooding risk: high & $-0.0702 * *$ & $-0.0667 * *$ & $-0.0537 *$ & $-0.0518^{*}$ & $-0.0536 *$ & $-0.0977 * *$ & $-0.0938 * *$ & $-0.0864 *$ & $-0.0868 *$ & $-0.0861 *$ \\
\hline Flooding risk: moderate & $-0.0856 * * *$ & $-0.0743 * * *$ & $-0.0773 * * *$ & $-0.0747 * * *$ & $-0.0726 * * *$ & $-0.0572 * *$ & $-0.0491 *$ & $-0.0554 * *$ & $-0.0494 *$ & $-0.0496 *$ \\
\hline Constant & $9.3582 * * *$ & $8.1611 * * *$ & $9.1297 * * *$ & $8.5411 * * *$ & $8.4252 * * *$ & $9.1534 * * *$ & $8.0948 * * *$ & $9.0790 * * *$ & $8.2697 * * *$ & $8.3036 * * *$ \\
\hline Observations & 697 & 697 & 697 & 697 & 697 & 697 & 697 & 697 & 697 & 697 \\
\hline R-squared / Squared correlation & 0.842 & 0.846 & 0.847 & 0.848 & 0.848 & 0.842 & 0.836 & 0.839 & 0.841 & 0.842 \\
\hline Lambda & & & & & & $0.645^{* * *}$ & $0.640 * * *$ & $0.629 * * *$ & $0.636 * * *$ & $0.632 * * *$ \\
\hline
\end{tabular}

${ }^{*}$ significant at $10 \% ;{ }^{* *}$ significant at 5\%; ${ }^{* * *}$ significant at $1 \%$ 
Table A3: Estimated impacts under scenario 3

\begin{tabular}{|c|c|c|c|c|c|c|c|c|c|c|}
\hline \multirow[t]{2}{*}{ Variables } & \multicolumn{5}{|c|}{ OLS } & \multicolumn{5}{|c|}{ GMM } \\
\hline & (1) & (2) & (3) & (4) & (5) & (6) & (7) & (8) & (9) & (10) \\
\hline Noise (LEQ) & $-0.0234 * * *$ & $-0.0186 * * *$ & $-0.0189 * * *$ & $-0.0169 * * *$ & $-0.0167 * * *$ & $-0.0236 * *$ & $-0.0197 * *$ & $-0.0207 * *$ & $-0.0184 * *$ & $-0.0185^{* *}$ \\
\hline Currency (=1 US dollars) & $0.2593 * * *$ & $0.2493 * * *$ & $0.2586 * * *$ & $0.2560 * * *$ & $0.2534 * * *$ & $0.2175^{* * *}$ & $0.2113 * * *$ & $0.2196 * * *$ & $0.2139 * * *$ & $0.2144 * * *$ \\
\hline Log of lot size & $0.2954 * * *$ & $0.3008 * * *$ & $0.2936 * * *$ & $0.3052 * * *$ & $0.3006 * * *$ & $0.2891 * * *$ & $0.2953 * * *$ & $0.2950 * * *$ & $0.2978^{* * *}$ & $0.2984 * * *$ \\
\hline Log of house size & $0.2808 * * *$ & $0.2648 * * *$ & $0.2759 * * *$ & $0.2638 * * *$ & $0.2651 * * *$ & $0.3309 * * *$ & $0.3196 * * *$ & $0.3201 * * *$ & $0.3145^{* * *}$ & $0.3142 * * *$ \\
\hline Stories (number) & $0.0997 * * *$ & $0.1036 * * *$ & $0.0973 * * *$ & $0.1033 * * *$ & $0.1016 * * *$ & $0.0943 * * *$ & $0.0977 * * *$ & $0.0945^{* * *}$ & $0.0969 * * *$ & $0.0971 * * *$ \\
\hline Bedrooms (number) & $0.0227 *$ & $0.0266 *$ & $0.0248^{*}$ & $0.0246 *$ & $0.0261 *$ & $0.0399 * *$ & $0.0422 * *$ & $0.0424 * *$ & $0.0439 * *$ & $0.0435^{* *}$ \\
\hline Baths (number) & $0.0536 * * *$ & $0.0525 * * *$ & $0.0540 * * *$ & $0.0516 * * *$ & $0.0526 * * *$ & $0.0381 * * *$ & $0.0349 * *$ & $0.0372 * * *$ & $0.0351 * * *$ & $0.0350 * * *$ \\
\hline House age (years) & -0.0007 & -0.0008 & -0.0007 & -0.0008 & -0.0008 & 0.0002 & -0.0000 & 0.0001 & -0.0000 & -0.0000 \\
\hline Garages (number) & $0.0586 * *$ & $0.0549 * *$ & $0.0559 * *$ & $0.0551 * *$ & $0.0544 * *$ & $0.0586 * *$ & $0.0575 * *$ & $0.0584 * *$ & $0.0573 * *$ & $0.0576 * *$ \\
\hline Condition: good (=1 yes) & $0.1023 * * *$ & $0.1051 * * *$ & $0.1004 * * *$ & $0.1033 * * *$ & $0.1030 * * *$ & $0.1405 * * *$ & $0.1410 * * *$ & $0.1381 * * *$ & $0.1392 * * *$ & $0.1391 * * *$ \\
\hline Condition: excellent (=1 yes) & $0.2165 * * *$ & $0.2128 * * *$ & $0.2137 * * *$ & $0.2183 * * *$ & $0.2143 * * *$ & $0.2283 * * *$ & $0.2302 * * *$ & $0.2279 * * *$ & $0.2289 * * *$ & $0.2294 * * *$ \\
\hline Time 2 (May) & $0.0796 * * *$ & $0.0852 * * *$ & $0.0833 * * *$ & $0.0844 * * *$ & $0.0856 * * *$ & $0.0681 * * *$ & $0.0701 * * *$ & $0.0696 * * *$ & $0.0708^{* * *}$ & $0.0707 * * *$ \\
\hline Time 3 (September) & $0.1429 * * *$ & $0.1476 * * *$ & $0.1450 * * *$ & $0.1495 * * *$ & $0.1485 * * *$ & $0.1151 * * *$ & $0.1187 * * *$ & $0.1178 * * *$ & $0.1197 * * *$ & $0.1199 * * *$ \\
\hline Distance to CBD $(\mathrm{km})$ & $-0.0910 * * *$ & $-0.0754 * * *$ & $-0.0806 * * *$ & $-0.0617 * * *$ & $-0.0680 * * *$ & $-0.0858 * * *$ & $-0.0613 * * *$ & $-0.0720 * * *$ & $-0.0587 * * *$ & $-0.0568 * * *$ \\
\hline Distance to CBD (Minutes) & 0.0051 & 0.0125 & 0.0031 & 0.0087 & 0.0087 & 0.0181 & 0.0248 & 0.0205 & 0.0252 & 0.0249 \\
\hline On avenue & & $0.0012 * * *$ & & $0.0008 * *$ & $0.0008^{* *}$ & & $0.0013 * *$ & & $0.0010 * *$ & $0.0010 * *$ \\
\hline Average hourly wage & & & $-0.8078^{* * *}$ & $-0.7063 * * *$ & $-0.6670 * * *$ & & & $-0.7470 * *$ & $-0.5635^{*}$ & $-0.5704 *$ \\
\hline \multicolumn{11}{|l|}{ Unemployment rate } \\
\hline Proportion of home and Land owners & & & & $-0.8479 * * *$ & $-0.7382 * * *$ & $-0.6984 * * *$ & & & $-0.8588 * * *$ & $-0.7501 * * *$ \\
\hline Flooding risk: high & $-0.0722 * *$ & $-0.0687 * *$ & $-0.0563 * *$ & $-0.0542 *$ & $-0.0560 *$ & $-0.0982 * *$ & $-0.0943 * *$ & $-0.0871^{*}$ & $-0.0874 *$ & $-0.0867 *$ \\
\hline Flooding risk: moderate & $-0.0880 * * *$ & $-0.0769 * * *$ & $-0.0796 * * *$ & $-0.0771 * * *$ & $-0.0750 * * *$ & $-0.0588 * *$ & $-0.0507 *$ & $-0.0569 * *$ & $-0.0510 * *$ & $-0.0512 * *$ \\
\hline Constant & $9.7473 * * *$ & $8.5886 * * *$ & $9.4663 * * *$ & $8.9099 * * *$ & $8.7973 * * *$ & $9.5021 * * *$ & $8.4538 * * *$ & $9.4245 * * *$ & $8.6265^{* * *}$ & $8.6607 * * *$ \\
\hline Observations & 697 & 697 & 697 & 697 & 697 & 697 & 697 & 697 & 697 & 697 \\
\hline R-squared / Squared correlation & 0.843 & 0.847 & 0.848 & 0.849 & 0.849 & 0.838 & 0.840 & 0.842 & 0.843 & 0.842 \\
\hline Lambda & & & & & & $0.644 * * *$ & $0.640 * * *$ & $0.630 * * *$ & $0.636 * * *$ & $0.632 * * *$ \\
\hline
\end{tabular}

${ }^{*}$ significant at 10\%; ** significant at 5\%; ${ }^{* * *}$ significant at $1 \%$ 
Table A4: Estimated impacts under scenario 4

\begin{tabular}{|c|c|c|c|c|c|c|c|c|c|c|}
\hline \multirow[t]{2}{*}{ Variables } & \multicolumn{5}{|c|}{ OLS } & \multicolumn{5}{|c|}{ GMM } \\
\hline & (1) & (2) & (3) & (4) & (5) & (6) & (7) & (8) & (9) & (10) \\
\hline Noise (LEQ) & $-0.0194 * * *$ & $-0.0167 * * *$ & $-0.0177 * * *$ & $-0.0163^{* * *}$ & $-0.0163^{* * *}$ & $-0.0182 * *$ & $-0.0212^{* * *}$ & $-0.0186 * *$ & $-0.0197 * * *$ & $-0.0182 * *$ \\
\hline Currency (=1 US dollars) & $0.2585^{* * *}$ & $0.2481 * * *$ & $0.2577 * * *$ & $0.2551 * * *$ & $0.2526 * * *$ & $0.2173 * * *$ & $0.2199 * * *$ & $0.2131 * * *$ & $0.2217 * * *$ & $0.2163 * * *$ \\
\hline Log of lot size & $0.3056 * * *$ & $0.3099 * * *$ & $0.3030 * * *$ & $0.3140 * * *$ & $0.3093 * * *$ & $0.3034 * * *$ & $0.2960 * * *$ & $0.3015^{* * *}$ & $0.3016^{* * *}$ & $0.3046 * * *$ \\
\hline Log of house size & $0.2766 * * *$ & $0.2595 * * *$ & $0.2700 * * *$ & $0.2579 * * *$ & $0.2592 * * *$ & $0.3107 * * *$ & $0.3275 * * *$ & $0.3158 * * *$ & $0.3158^{* * *}$ & $0.3098 * * *$ \\
\hline Stories (number) & $0.1030 * * *$ & $0.1065 * * *$ & $0.0999 * * *$ & $0.1058 * * *$ & $0.1040 * * *$ & $0.0955 * * *$ & $0.0942 * * *$ & $0.0977 * * *$ & $0.0945^{* * *}$ & $0.0971 * * *$ \\
\hline Bedrooms (number) & $0.0237 *$ & $0.0280 * *$ & $0.0263^{*}$ & $0.0260 *$ & $0.0276 * *$ & $0.0446 * * *$ & $0.0412 * *$ & $0.0435^{* *}$ & $0.0438^{* * *}$ & $0.0449 * * *$ \\
\hline Baths (number) & $0.0501 * * *$ & $0.0496 * * *$ & $0.0510 * * *$ & $0.0488 * * *$ & $0.0499 * * *$ & $0.0336 * *$ & $0.0359 * * *$ & $0.0331 * *$ & $0.0353 * * *$ & $0.0334 * *$ \\
\hline House age (years) & -0.0008 & -0.0009 & -0.0008 & -0.0009 & -0.0009 & 0.0002 & 0.0001 & -0.0001 & -0.0000 & -0.0001 \\
\hline Garages (number) & $0.0596 * * *$ & $0.0558 * *$ & $0.0570 * *$ & $0.0562 * *$ & $0.0555 * *$ & $0.0567 * *$ & $0.0577 * *$ & $0.0568 * *$ & $0.0577 * *$ & $0.0571 * *$ \\
\hline Condition: good (=1 yes) & $0.0944 * * *$ & $0.0989 * * *$ & $0.0939 * * *$ & $0.0975^{* * *}$ & $0.0972 * * *$ & $0.1357 * * *$ & $0.1381 * * *$ & $0.1389 * * *$ & $0.1357 * * *$ & $0.1370 * * *$ \\
\hline Condition: excellent (=1 yes) & $0.2087 * * *$ & $0.2062 * * *$ & $0.2069 * * *$ & $0.2123 * * *$ & $0.2081 * * *$ & $0.2234 * * *$ & $0.2251 * * *$ & $0.2273 * * *$ & $0.2248 * * *$ & $0.2266 * * *$ \\
\hline Time 2 (May) & $0.0801 * * *$ & $0.0858 * * *$ & $0.0838 * * *$ & $0.0848 * * *$ & $0.0861 * * *$ & $0.0719 * * *$ & $0.0686 * * *$ & $0.0705^{* * *}$ & $0.0702 * * *$ & $0.0712 * * *$ \\
\hline Time 3 (September) & $0.1444 * * *$ & $0.1491 * * *$ & $0.1466 * * *$ & $0.1511 * * *$ & $0.1500 * * *$ & $0.1219 * * *$ & $0.1161 * * *$ & $0.1197 * * *$ & $0.1189 * * *$ & $0.1210 * * *$ \\
\hline Distance to CBD $(\mathrm{km})$ & $-0.0986 * * *$ & $-0.0819 * * *$ & $-0.0877 * * *$ & $-0.0682 * * *$ & $-0.0748 * * *$ & $-0.0641 * * *$ & $-0.0932 * * *$ & $-0.0682 * * *$ & $-0.0793 * * *$ & $-0.0638 * * *$ \\
\hline Distance to CBD (Minutes) & 0.0125 & 0.0193 & 0.0100 & 0.0152 & 0.0151 & 0.0301 & 0.0233 & 0.0293 & 0.0253 & 0.0293 \\
\hline On avenue & & $0.0012 * * *$ & & $0.0008^{* *}$ & $0.0008^{* *}$ & $0.0010 *$ & & $0.0013 * * *$ & & $0.0010 * *$ \\
\hline \multicolumn{11}{|l|}{ Average hourly wage } \\
\hline Unemployment rate & & $0.2178 *$ & 0.1519 & & 0.1639 & -0.0441 & & -0.0154 & -0.0218 & -0.0360 \\
\hline Proportion of home and Land owners & & & $-0.8588 * * *$ & $-0.7501 * * *$ & $-0.7089 * * *$ & $-0.6049 *$ & & & $-0.7669 * *$ & $-0.5881 *$ \\
\hline Flooding risk: high & $-0.0656 * *$ & $-0.0632 * *$ & $-0.0497 *$ & $-0.0482 *$ & $-0.0502 *$ & & $-0.0918 * *$ & $-0.0888 * *$ & $-0.0809 *$ & $-0.0811^{*}$ \\
\hline Flooding risk: moderate & $-0.0754 * * *$ & $-0.0660 * * *$ & $-0.0683 * * *$ & $-0.0669 * * *$ & $-0.0648 * * *$ & & $-0.0495^{*}$ & $-0.0426 *$ & $-0.0483 *$ & $-0.0434 *$ \\
\hline Constant & $9.4388 * * *$ & $8.4010 * * *$ & $9.3698 * * *$ & $8.8626 * * *$ & $8.7599 * * *$ & $8.6573 * * *$ & $9.3109 * * *$ & $8.3502 * * *$ & $9.3349 * * *$ & $8.6276 * * *$ \\
\hline Observations & 697 & 697 & 697 & 697 & 697 & 697 & 697 & 697 & 697 & 697 \\
\hline R-squared / Squared correlation & 0.844 & 0.847 & 0.849 & 0.849 & 0.850 & 0.838 & 0.841 & 0.843 & 0.844 & 0.844 \\
\hline Lambda & & & & & & $0.617 * * *$ & $0.634 * * *$ & $0.628 * * *$ & $0.617 * * *$ & $0.619 * * *$ \\
\hline
\end{tabular}

*significant at 10\%; ** significant at 5\%; ${ }^{* *}$ significant at 1 